\title{
Degradation of architectural precast concrete elements on the facade of St. Michael the Archangel church in Warsaw
}

\author{
Grzegorz Adamczewski ${ }^{1,2,}$, and Piotr Woyciechowski ${ }^{2}$ \\ ${ }^{1}$ Stowarzyszenie Producentów Betonów, ul. Mączeńskiego 2, 02-829 Warszawa, Polska \\ ${ }^{2}$ Warsaw University of Technology, Al. Armii Ludowej 16, 00-637 Warszawa, Polska
}

\begin{abstract}
The paper presents the case study of the degradation of architectural precast concrete elements on the facade of St. Michael the Archangel church in Warsaw. The background of the contemporary precast non-standard prefabrication was presented with the examples of polish recent applications. The GPR (ground penetrating radar) method was used in determining the location of reinforcement in the precast elements in the degraded façade. The conceptions of repair were analyzed and the reasons of the destructions of the precast elements.
\end{abstract}

\section{Contemporary non-standard prefabrication}

Concrete prefabrication gives wide possibilities for shaping the structure, spatial form and aesthetics. This allows to create objects in accordance with the vision of architects and the expectations of investors and users. Wide use and recognition of investors find non-standard individually designed elevations, especially public buildings (Fig. 1). Wall elements of atypical shapes and openwork can also be used as internal partitions allowing to arrange interesting interiors [1].

The precast technology is also used in the implementation of non-standard structures such as churches. An example of the construction of prefabricated structures is, for example, the construction of a neo-Baroque church (Fig. 2). In the aforementioned case, prefabricated reinforced concrete girders with a span of up to $12 \mathrm{~m}$ were made. For technological reasons, the largest element ( 32 tons) of the nave has been divided into two elements. The construction of the church also used prefabricates of a different type, including the covering of the arched ceiling. The vault was made as a composite slab prefabricated-monolithic in the form of filigree ceiling shells. The use of prefabricated elements in sacred building has a long tradition in Poland. The post-war example of the use of prefabricated elements for the implementation of the church facade is the church of St. Michael the Archangel in Warsaw, which is the subject of this publication (Fig. 3).

\footnotetext{
${ }^{*}$ Corresponding author: g.adamczewski@il.pw.edu.pl
} 


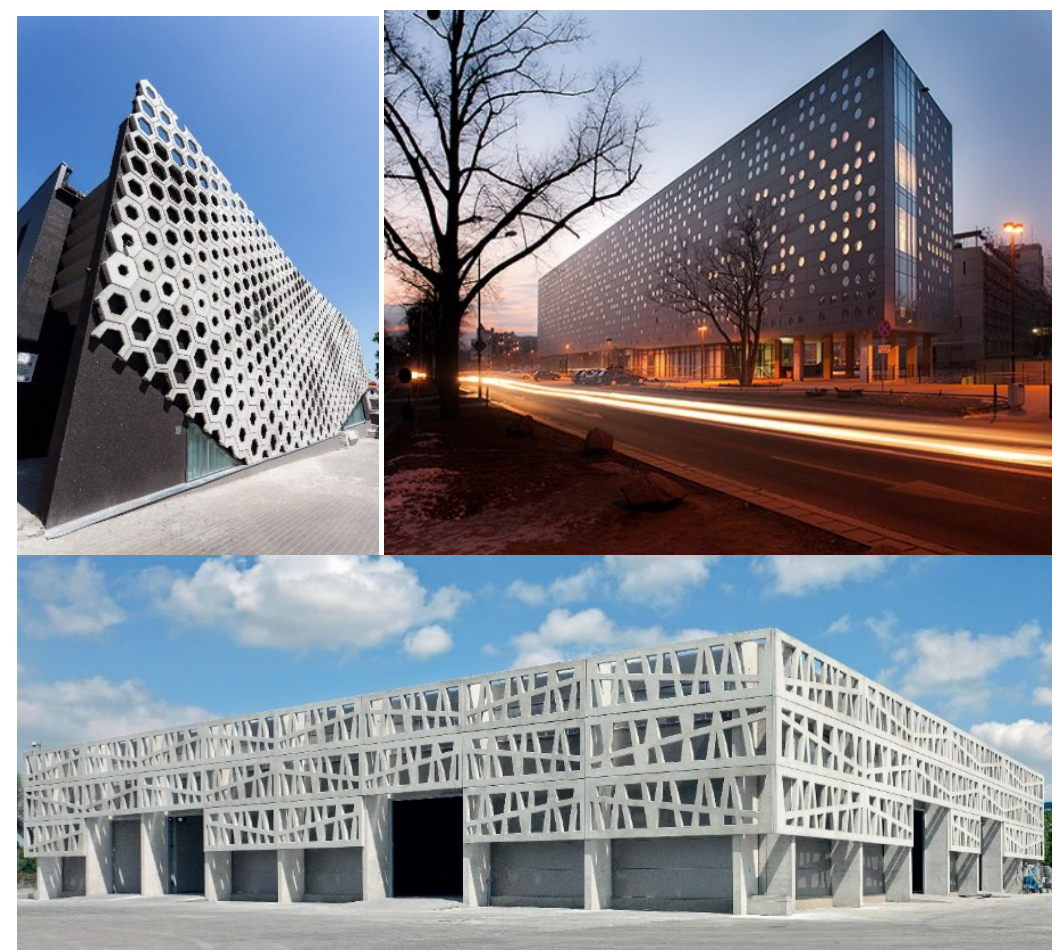

Fig. 1. Non-standard elevations in public buildings [1].

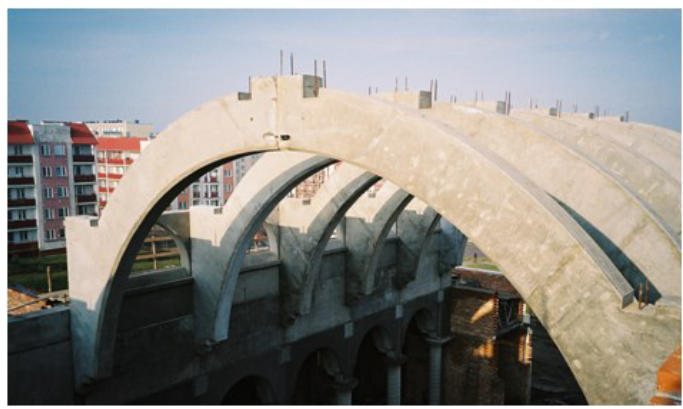

Fig. 2. Prefabricated elements in the church construction [1].

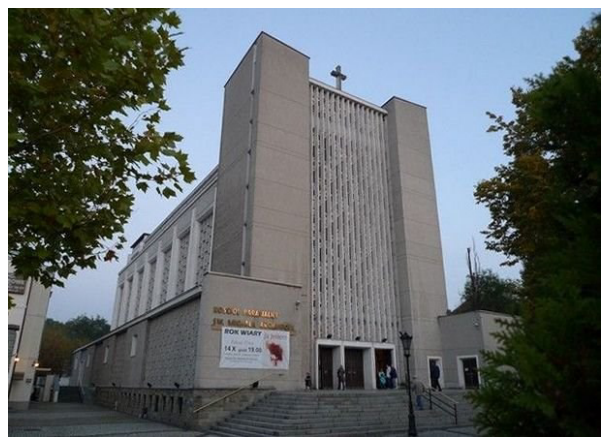

Fig. 3. Church of Saint. Michael the Archangel in Warsaw (http://archwwa.pl/parafie/warszawa-swmichala-archaniola/). 
The durability of contemporary designed structures according to Eurocode 0 is - along with bearing capacity and usability - one of three basic assumptions in the design process and has a significant impact on the adopted construction and material solutions. According to Eurocode 2, the durability of the facility is maintained if, within the assumed time frame, the structure fulfills its functions in the field of usability (limit states related to limiting stresses, cracks and deflections), load capacity and stability (ultimate limit states). Proper design of the structure ensures that the performance requirements are met at least for the period of expected durability. In fact, the durability of the erected structure is, however, fraught with a significant level of uncertainty, resulting, on the one hand, from design, implementation and material defects, and on the other from the limited predictability of impacts related to the conditions of use.

The required durability in monumental buildings, to which sacred objects belong, exceeds 50 years, accepted according to PN-EN 206 as the basic period of concrete durability, provided in the case of meeting the requirements for composition and components given in this standard for individual concrete exposure classes. It is worth noting that in the case of prefabricates, especially rods, tightened requirements and quality control refer to the content of chloride ions and limitations related to the risk of ASR/ACR reaction, especially in cases of compressed or heat treated components.

Shaping the durability of concrete elements includes activities undertaken at all stages of their formation, including at the stage of designing, selection, production and supply of materials, as well as technology of building construction.

The key step in designing a concrete element is durability, depending on required concrete cover thickness. This selection takes into account environmental conditions of exploitation (exposure class), as well as conditions of adhesion of concrete to reinforcement and fire resistance of the element.

\section{Identification of façade elements defects}

The church was erected in the 50/60 of the last century, in a mixed technology, using numerous prefabricated elements that constitute architectural elevation elements (Fig. 4). Advanced damage to precast concrete occurred only on the front facade elements of the church. The aim of the research was to assess the condition of prefabricated concrete elements of the front (west) façade and to develop a general repair concept. 
a)
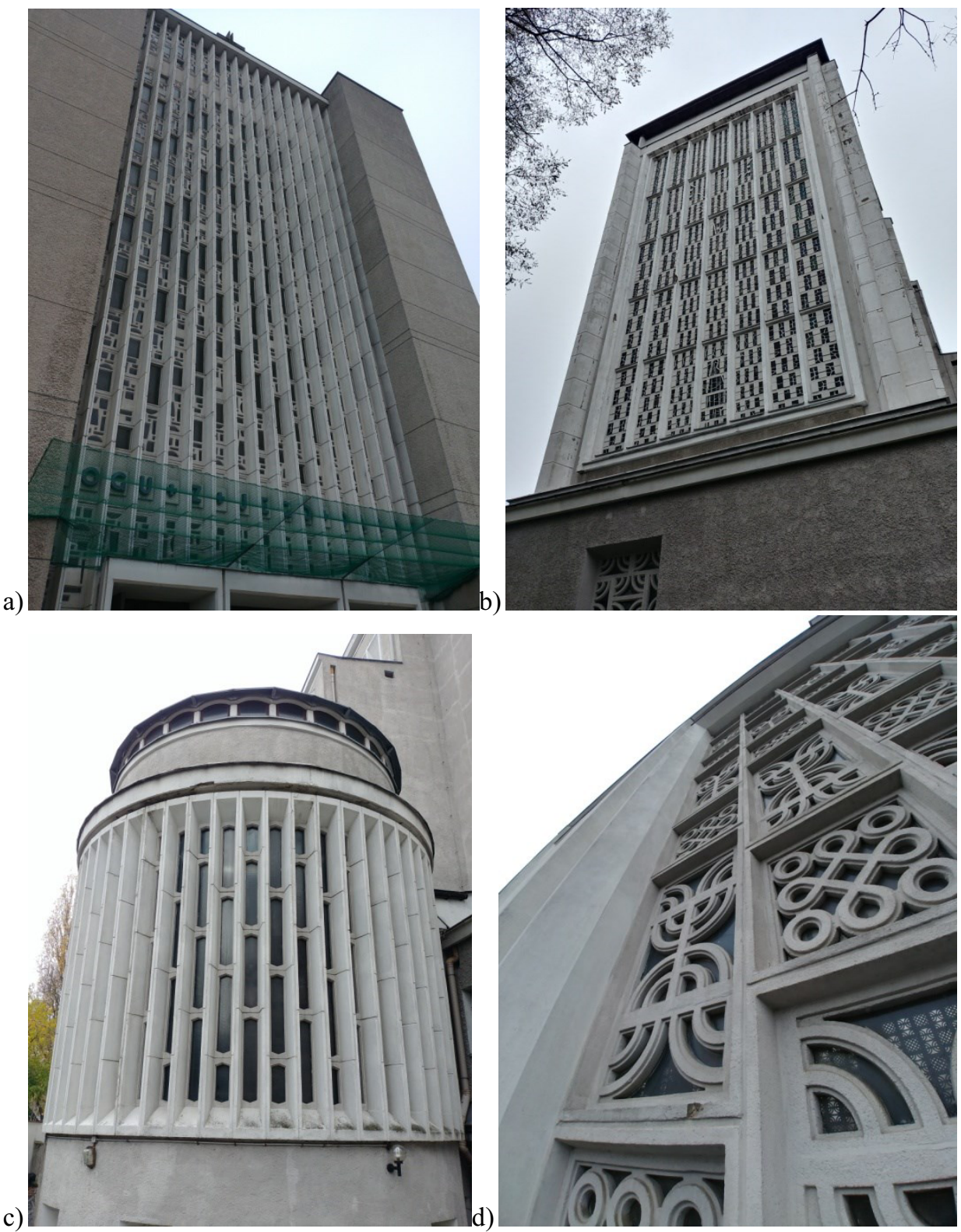

Fig. 4. Prefabricated elements of the church on the front façade (a) and on the other façades (b, c, d).

Extensive damage to façade elements has been found. They include the detachment of the outer vertical edges of the elements (Fig. 5) and the horizontal cracking of the elements from the inside. Cracks in the inside usually run horizontally around the height of the element (Fig. 6). Separation from the outside applies to virtually all elements on the entire height of the façade (Fig. 7). Damage to the elements from the outside runs along the reinforcing bars and applies to the entire thickness of the reinforcement cover (Fig. 8). 

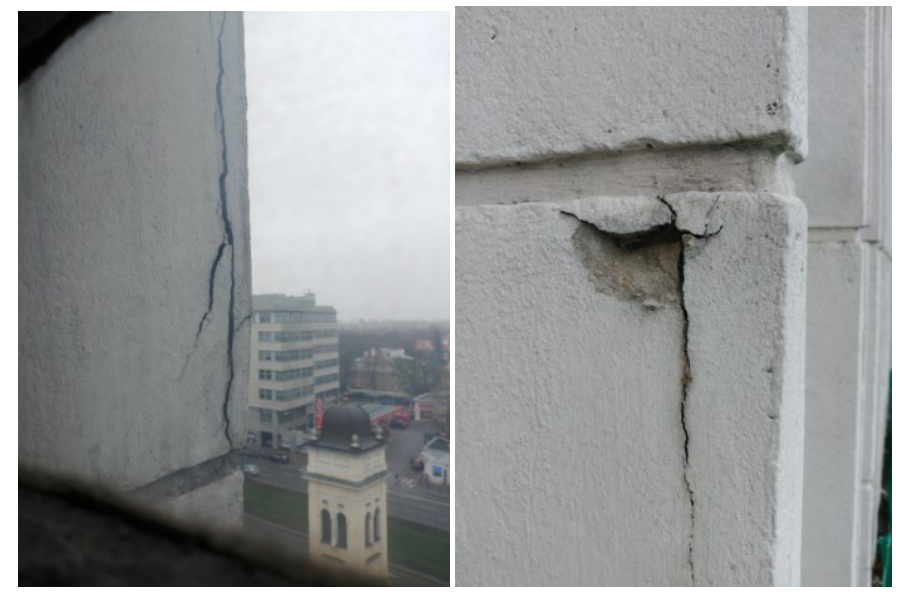

Fig. 5. Delaminations of the outer edges of the elements.

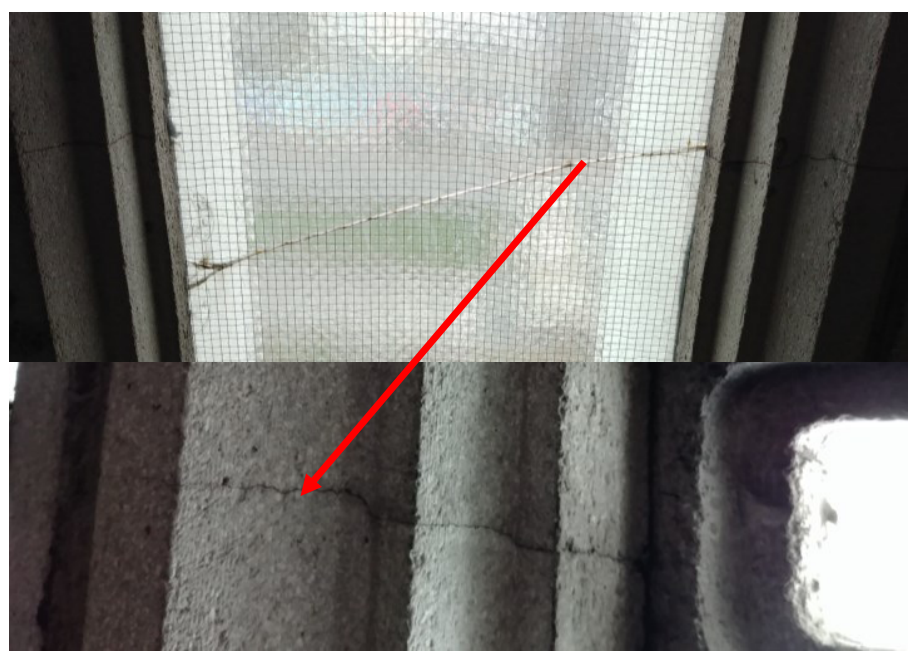

Fig. 6. Cracks from the inside in the middle of the span of the element. 


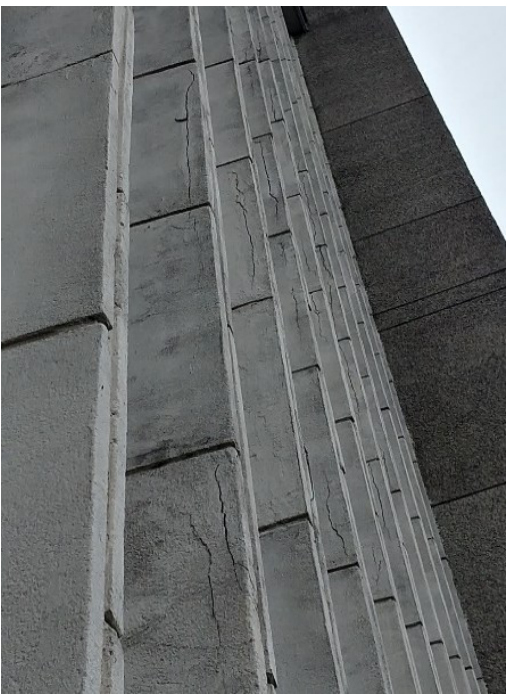

Fig. 7. Extensive damage to façade elements.

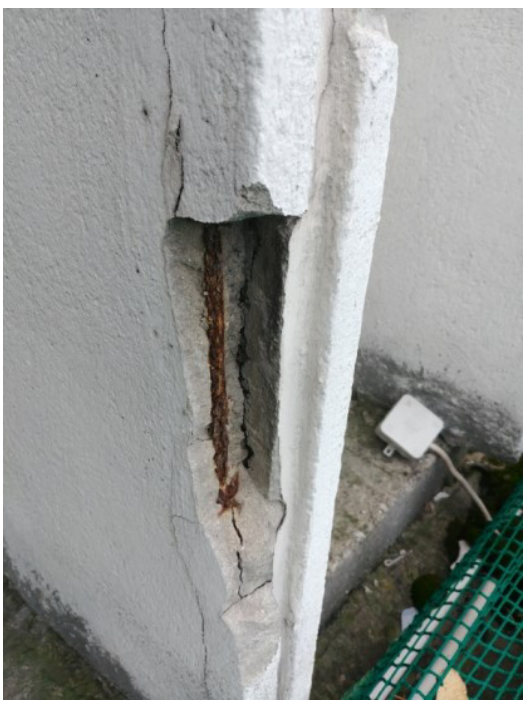

Fig. 8. The insulation of the reinforcement cover.

\subsection{Assessment of the thickness of the concrete cover and the degree of its carbonation}

In the first stage of the diagnostics, the thickness of the reinforcement cover from the outer side of the façade was evaluated in two planes, by open-pit method in several places. Example of measurements in a plane perpendicular to the façade (Fig. 9a) and in a plane parallel to the façade (Fig. 9b). The thickness of the concrete cover from the outside surface fluctuated within the limits of 35-40 $\mathrm{mm}$, while from the side surface $-15-17 \mathrm{~mm}$.

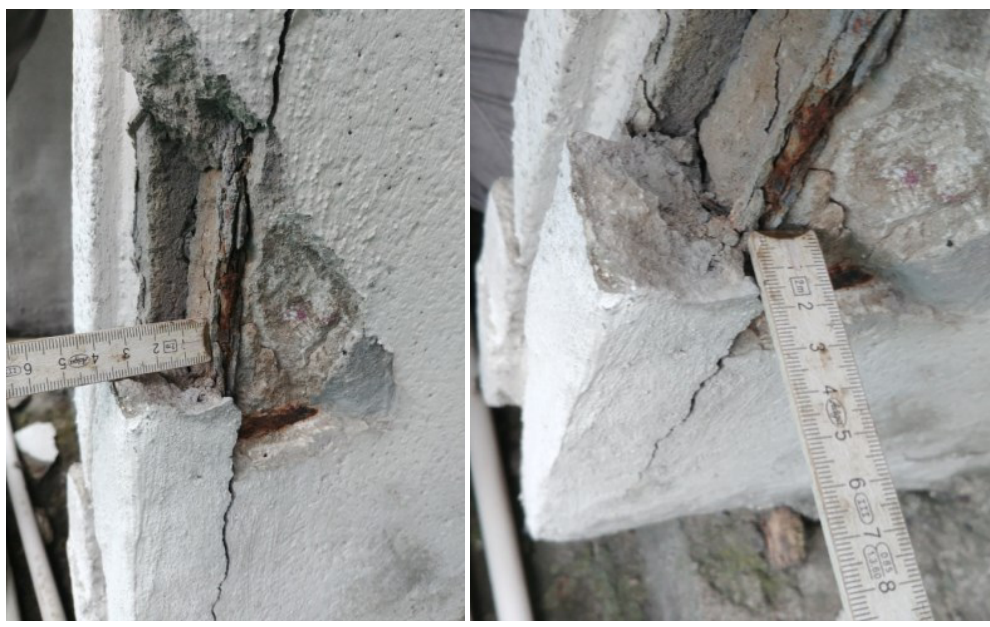

Fig. 9. Estimated thickness of the concrete cover: a) from the outer surface (edge of the element) approx. 30-40 $\mathrm{mm}$; b) from the lateral surface approx. $15-17 \mathrm{~mm}$.

In the second stage of diagnostics, carbonation depth tests were carried out. These tests were performed on fresh (made just before the test) forgings of structural elements using phenolphthalein indicator, which allows to determine the $\mathrm{pH}$ front limit equal to 8.3. The procedure for making the marking was in accordance with the PN-EN 14630 standard and included: making the forging, wetting its surface with distilled water, applying a 
phenolphthalein solution, measuring the depth of the carbonation front. An example of the test result is shown in Fig. $9 \mathrm{~b}$ and 10.

The difference in the result is visible in both cases documented in the pictures. In the photo $6 \mathrm{~b}$ probably the primary material of the prefabricated element (sand concrete) is visible and there is no untreated, i.e. unfinished, area on the surface of the forging. This explains the strong corrosive state of the visible rod and a significant loss of its cross-section as a result of the separation of mechanically weak corrosion products.

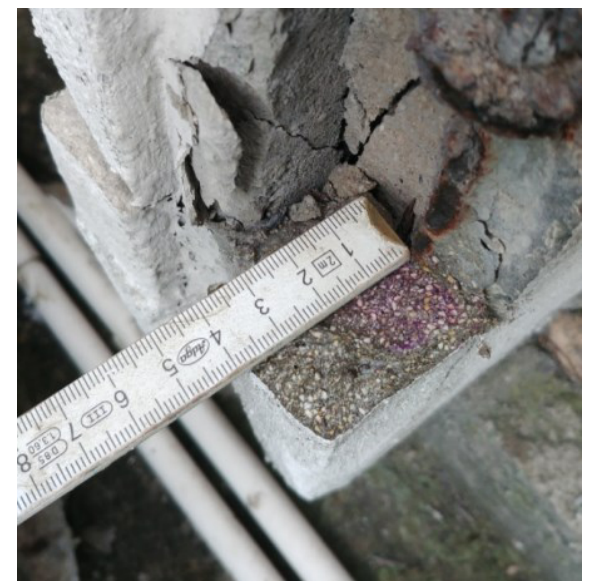

Fig. 10. Range of the carbonated zone.

In the case of the forge shown in Fig. 7, another material - presumably used for local repair - is also visible - also freshly grained, but with a clearly visible fine aggregate $2 / 4 \mathrm{~mm}$. This material is also carbonated but to a limited extent: approx. $20 \mathrm{~mm}$ from the external surface and approx. $7 \mathrm{~mm}$ from the lateral surface. The difference probably arises from a different exposure to the atmospheric conditions of both surfaces and the associated different durability of the painting trip on the surface of the element. The corrosion condition of the rod visible in Fig. 7 is probably the pre-repair situation, but in the present situation the carbonation stability of the repair layer is also depleted and further progress of corrosion of the reinforcement is to be expected.

\section{Identification of the reinforcement bar locations}

The aim of the study was to determine the location of reinforcing bars. The tests were carried out using the Ground Penetrating Radar (GPR) method [2, 3] and the execution of local opencasts from the self-supporting lagging of the rods. The GPR method is a noncontact technique, the operating principle of which is very similar to the echo method most often used in ultrasonic flaw detection, but instead of elastic waves, electromagnetic waves are used. The difference in the dielectric properties of the two materials determines the amount of reflected wave energy that is recorded by the antenna (Fig. 8). 

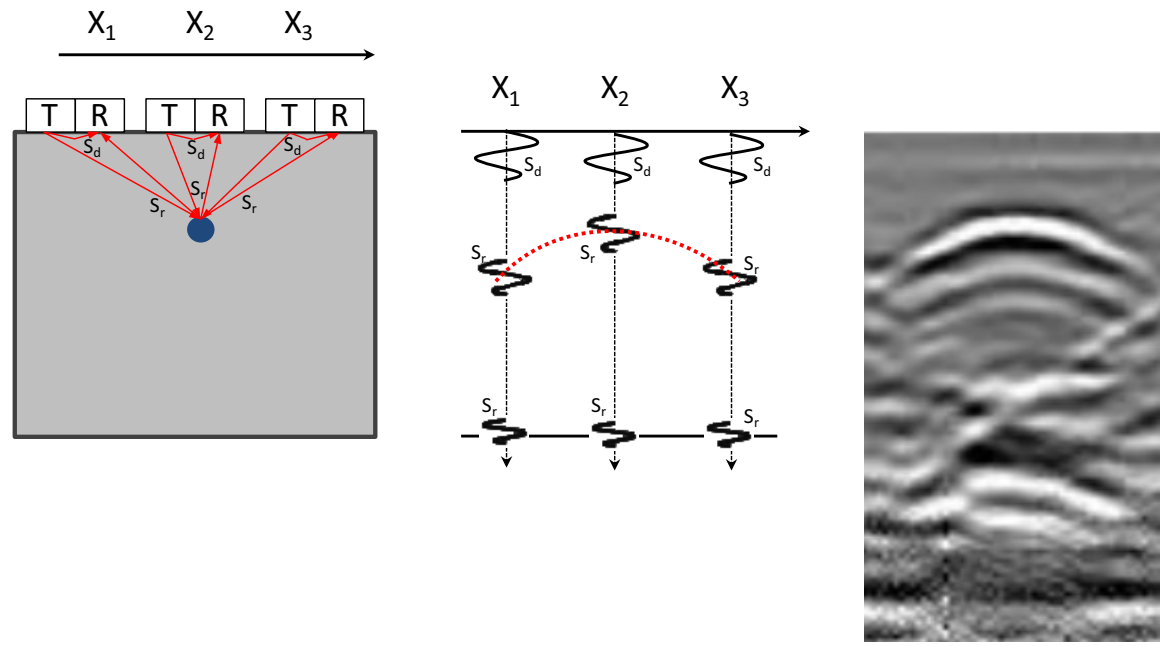

Fig. 11. Principle of GPR testing.

In typical construction applications, the radar is used to detect delamination and defects and the location of reinforcing bars in reinforced concrete elements (Fig. 12).

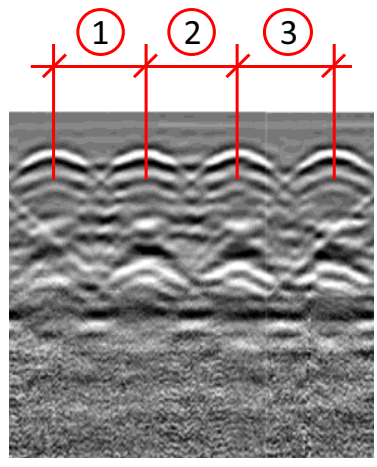

Fig. 12. Location and determination of spacing of reinforcing bars in a reinforced concrete element. 

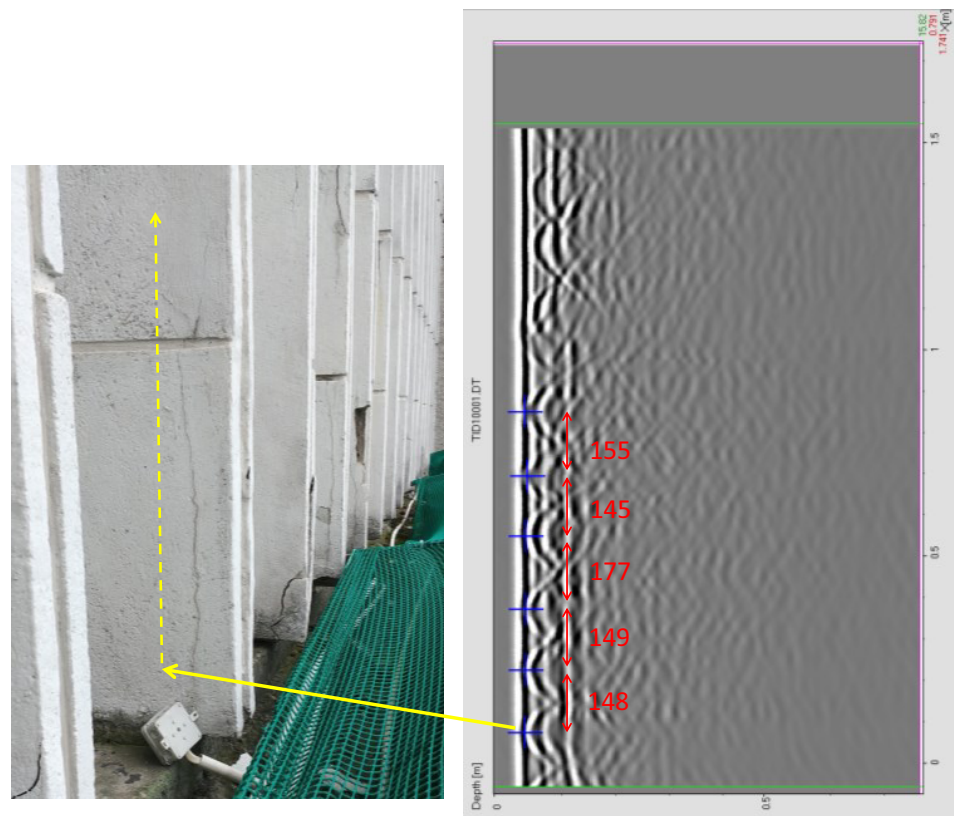

Fig. 13. A radar image made along the side surface of the element - identification of reinforcing bars.

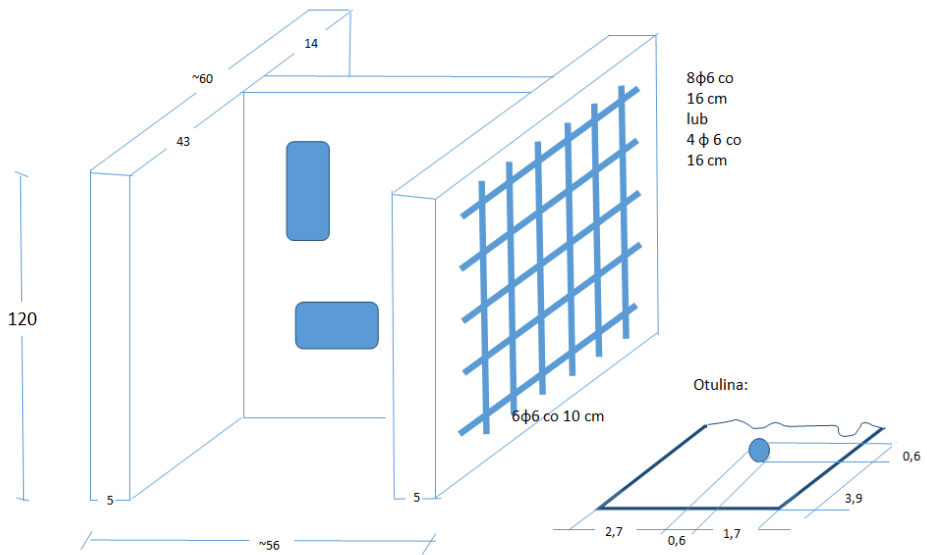

Fig. 14. Sketch of the probable arrangement of reinforcing bars in the element.

The radar images indicate a horizontal spacing of bars of the order of $150-170 \mathrm{~mm}$ and a vertical spacing of bars of $100-120 \mathrm{~mm}$. The made opencasts indicate that the reinforcement of prefabricated elements was made of $\varphi 6 \mathrm{~mm}$ bars. It should be assumed that adjacent prefabricated elements are connected with each other by horizontal steel connectors placed on one side at the height of the element, and on the other - at the contact of adjacent vertical elements. The exact identification of the connectors is only possible in an invasive way when disassembling or deep excavation.

The sketch of the probable arrangement of reinforcing bars in the element is shown in Fig. 14. The height of all elements is $120 \mathrm{~cm}$, except for the "half" elements occurring in a given vertical section on the top or bottom edge of the façade. 


\section{Causes of damage}

The causes of damage to the elements of prefabricated façades are very complex. They are connected with the stage of designing elements according to standards from more than half a century, as well as with the quality of contemporary materials and low production standards in comparison to modern prefabricated factories.

The concrete used in the elements was characterized by very fine graining and probably a relatively low cement content. The cover made in the case of the side surfaces of the elements was even only a dozen or so millimeters. The reinforcement of the elements is made of smooth bars $\varnothing 6 \mathrm{~mm}$. These material characteristics would be unacceptable in the light of current prefabrication design standards. Accepted materials of low quality and a small degree of reinforcement of elements also affected their general stiffness while working in a self-supporting facade wall - this was reflected in the regular arrangement of cracks running horizontally, usually at the height of individual elements.

It is also necessary to take into account the environmental changes located in the outside of the strict center of Warsaw, which, as the capital developed, found itself in a more aggressive zone of urban pollution impact, which caused extensive dehumidification in virtually all of the analyzed elements.

However, it should be noted that despite the factors limiting durability indicated above, these elements have their function for around 60 years. This value is highly satisfactory, especially as it refers to elements that do not constitute the supporting structure of the object.

\section{Repair concepts}

In the current façade state, a proper general strategy for the assessment of the façade is required [4-6]. Degree of damage to façade elements - including extensive destruction from the outside covering not only the concrete cover but also reinforcement in the majority of elements and numerous scratches from the interior of the church, indicates that the most appropriate option may be a complete replacement of façade elements for new ones constituting a replica of the original in the aesthetic sense, but designed and made taking into account the latest material and technological solutions. An alternative is to develop a comprehensive repair project that takes into account the fact of deep destruction of concrete and reinforcement of elements, as well as stability analysis of the partition.

The final decision on the choice of scenario should be based on an analysis that takes into account technical aspects of the implementation of the work, their cost-effectiveness and applicable regulations, including the fact that the object is historic. The total cost of repairs / repairs and the forecast of the effects of the actions taken are to be taken into account in relation to the expected lifetime of the facility after repair.

An additional aspect that can be taken into account in the decision-making process is the issue of the need for thermo-modernization of church partitions. Possible actions in this respect cannot interfere with the appearance of the façade, which generally hinders the modernization of the existing solution and seems to speak for the variant covering the execution of the new façade.

\section{Repair of elements.}

Repair of elements should be made on the basis of a repair project prepared by the selected contractor (design and build) using an effective concrete repair technology. The state of destruction of the outer surfaces of the façade indicates that all elements should be covered by the repair. The scope of the repair should include restoring the load-bearing capacity of the elements as well as restoring the appearance of the façade and ensuring the durability of the elevation. In addition, the following aspects of implementation should be noted: 
- $\quad$ security of the works front,

- safety in the area of health and safety,

- extensive nature of damage,

- very far-advanced corrosion of concrete and reinforcement of elements.

In particular, this means the necessity to use high-quality repair materials and repair technology, based on the recommendations contained in the standards of the PN-EN 1504 series.

General recommendations regarding the course of repair:

- stability analysis of the partition in the context of its original structure and the degree of its degradation, taking into account the own weight of the structure, utilitarian and wind loads,

- removal of loose and loose parts of concrete elements on the entire height of the façade,

- thorough cleaning (e.g. by abrasive blasting) of the exposed reinforcement surfaces of the elements to obtain the cleanliness effect of Sa 2.5 steel; in areas where a significant reduction of reinforcement sections may be found, it may be necessary to restore or reinforce the element, e.g. with carbon fiber tapes,

- protection of the surface exposed as a result of cleaning, using a material acting as a tacking bridge (preferably that the material contains corrosion inhibitors),

- filling cavities and reprofiling elements with a repair material with granulation resulting from the required thickness of the reprofiling layer,

- protection of the surface with anti-corrosive function.

It is recommended that the materials used constitute a repair system from one manufacturer of construction chemicals, ensuring compatibility of system components.

\section{Replacement of elements}

Newly designed and made elements should visually match the original elements, in particular in terms of their external appearance, geometry and color. In the construction design of the entire façade of the new elements it is advisable to consider the actual stiffness of the barrier and its work in the construction, using the observation of the nature of lateral scratches of existing prefabricated elements. Depending on the decision of the Investor and the law, it is possible to consider the modification of elements aimed at improving the energy efficiency of the partition (lowering the U-coefficient of the element).

Elements should be made according to a separate project prepared by a designer with appropriate qualifications and in agreement with the architectural and construction administration authorities. It is recommended to consider the desirability of replacing the traditional reinforcement with non-metallic reinforcement in the form of bars or dispersed reinforcement (fibers), making the element from polymer-cement concrete or geopolymers intended for such applications. A renowned pre-cast producer should be a participant of the project from the design phase. 


\section{Summary}

Based on the inspection carried out, the emergency condition of the concrete elements of the façade was confirmed. The degree of destruction of the concrete of the concrete cover is very advanced and threatens the safety of the object due to the falling fragments of concrete. In addition, lateral scratches of numerous elements visible on the inner surface of the façade indicate an existing risk of loss of stability of the whole façade, due to which remedial measures should be taken immediately. Due to the advanced degree of damage to the elements, the choice of façade repair concept consisting in the replacement of prefabricated elements with new ones seems to be more rational. Such a solution using contemporary elements of high quality and durability would guarantee a long-term operation of the facility. The modern prefabrication allows to perform elements that meet such requirements due to current design procedures taking into account environmental impacts and high quality of materials and products controlled at the production and assembly stage.

The Authors would like to kindly thank the Parson of the St. Michael the Archangel church in Warsaw, fr. dr Jan Konarski for the cooperation in time of carrying the expertise work

\section{References}

1. G. Adamczewski, P. Woyciechowski, Prefabrykacja-jakość, trwatość, różnorodność, Zeszyt 1 (SBPB, Warszawa, 2014) [in Polish]

2. G. Adamczewski, A. Garbacz, T. Piotrowski, K. Załęgowski, Materiały Budowlane, 9, 2-5, (2013) [in Polish]

3. G. Adamczewski, A. Garbacz, A. Wiellen, T. Piotrowski, L. Courard, Zastosowanie metody GPR do oceny jakości zespolenia w układach naprawczych (Proceedings of the $41^{\text {st }}$ Conference „Krajowa Konferencja Badań Nieniszczących”, Toruń, pp. 232-234, 2012) [in Polish]

4. L.E. Czarnecki, P. Łukowski, A. Garbacz, Naprawa i ochrona konstrukcji z betonu. Komentarz do PN-EN 1504 (Państwowe Wydawnictwo Naukowe, Warszawa, 2017)

5. B. Bissonnette, A. Garbacz, F. Modjabi-Sangnier, A.M. Vaysburd, Quantitative approaches to concrete repair compatibility (Proceedings of XXVIII Scientific-Technical Conference on Structural Failures, Szczecin-Międzyzdroje, pp. 857-866, 2017)

6. B. Bissonnette, L. Courard, A. Garbacz, A.M. Vaysburd, K. Fay, Development of Specifications and Performance Criteria for Surface Preparation Based on Issues Related to Bond Strength (No. Final Report ST-2017-2886-1) (2017) 